\title{
EFFECTS OF FLOUR OR FLAXSEED OIL UPON INTRA-ABDOMINAL ADIPOSITY IN MALE RATS SUBJECTED TO EARLY WEANING
}

\author{
B. Ferolla da Camara Boueri ${ }^{1}$, C. Ribeiro Pessanha ${ }^{1}, A . D^{\prime}$ Avila Pereira ${ }^{1}$, D. Cavalcante Ribeiro', \\ A. de Sousa dos Santos ${ }^{2}$, C.C. Alves do Nascimento-Saba², C.A. Soares da Costa ${ }^{1}$ G. Teles Boaventura ${ }^{1}$
}

\begin{abstract}
The present study was designed to evaluate intra-abdominal adiposity in rats subjected to early weaning and subsequently treated with diet containing flour or flaxseed oil until young life. Pups were weaned for separation from mothers at 14 days (early weaning, EW), and 21 days (control, C). After 21 days, control (C60) was fed with control diet. EW was divided into control (EWC60); flaxseed flour (EWFF60); flaxseed oil (EWFO60) diets until 60 days. At 21-60 day, intra-abdominal fat mass were evaluated. At 60 days, retroperitoneal adipocyte area was determined. At 21 days, EW group displayed lower $(\mathrm{P}<0.05)$ intraabdominal fat mass. At 60 days, EWC60 group displayed lower $(\mathrm{P}<0.05)$ intra-abdominal fat mass. Adipocytes area were lower $(\mathrm{P}<0.05)$ in experimental groups. EWC60 displayed lower $(\mathrm{P}<0.05)$ adipocytes area (vs. EWFF60 and EWFO60). Flour and flaxseed oil diets contribute to recovery of intra-abdominal adiposity after precocious interruption of lactation..
\end{abstract}

Key words: lactation, adipocytes, morphometry, development.

\section{Introduction}

Overweight and obesity are a public health problem in both developed countries and those in development.1 Studies suggest the importance of the first few years of life in establishing healthy patterns of growth and that breastfeeding may be a protective factor childhood obesity (1-3). According to the World Health Organization, exclusive breastfeeding is recommended for the first six months of life, followed by breastfeeding in combination with the introduction of complementary foods until at least 12 months of age. However, no more than $35 \%$ of infants worldwide are exclusively breastfed during the first months of life $(4,5)$.

In 1958 British cohort study, Parsons et al. (6) identified a J-shape curve in which restricted nutrition and low weights in early life is correlated with subsequent obesity at age thirty-three. Given the prevalence of precocious interruption of breastfeeding in humans, animal models emulating this phenomenon might provide

1. Laboratory of Experimental Nutrition, Departament of Nutrition and Dietetics, Fluminense Federal University, Niterói, RJ, Brazil; 2. Physiological Sciences, Institute of Biology Roberto Alcantara Gomes, State University of Rio de Janeiro, Rio de Janeiro, RJ, Brazil.

Corresponding Author: Carlos Alberto Soares da Costa. Laboratory of Experimental Nutrition, College of Nutrition, Fluminense Federal University. Rua Mário Santos Braga, 30, Niterói, RJ, 24015-110, Brazil. E-mail: nutcarlos@hotmail.com Telephone and fax number: +552126299860

Received September 13, 2016

Accepted for publication January 3, 2017 useful information regarding deleterious effects of this procedure (7) on higher adiposity development. Previously, in experimental models, Maia et al. (8) and Boueri et al. (9) reported that early weaning decreases body adipogenesis at 21 days. Compared to adult life in human (10), Nobre et al. (11) related that early weaning programmed for higher visceral fat mass in rat at 180 days, corroborating the J-shape curve identified by Parsons et al. (6)

Lactation is a critical period for the programming of obesity. Indeed, hiperlipidic diet immediately after growth retardation induces a catch-up growth and leads to the programming of obesity at adulthood (12). However, normolipidic diet containing flaxseed (Linum usitatissimum) has potential to promote adipocyte hypertrophy down-regulation (13, 14). And considering that adult obesity prevention trials have largely focused on schoolchildren or adolescents (15), the present study was designed to evaluate intra-abdominal adiposity in rats subjected to early weaning and subsequently treated with diet containing flour or flaxseed oil until young life.

\section{Materials and methods}

The protocol used to deal with experimental animals was approved by Ethics Committee on Animal Research of Fluminense Federal University, Niteroi-RJ, Brazil 
EFFECTS OF FLOUR OR FLAXSEED OIL UPON INTRA-ABDOMINAL ADIPOSITY IN MALE RATS SUBJECTED TO EARLY WEANING.

Table 1

Intra-abdominal adiposity at 60 days

\begin{tabular}{|c|c|c|c|c|}
\hline & $\mathrm{C} 60$ & EWC60 & EWFF60 & EWFO60 \\
\hline Intra-abdominal fat mass $(\mathrm{g} / 100 \mathrm{~g})$ & $3.530 \pm 0.353^{\mathrm{a}}$ & $2.500 \pm 0.162^{\mathrm{b}}$ & $3.406 \pm 0.135^{\mathrm{a}}$ & $3.267 \pm 0.250^{\mathrm{a}}$ \\
\hline Gonadal fat mass (g) & $4.469 \pm 0.409^{\mathrm{a}}$ & $3.109 \pm 0.278^{b}$ & $4.517 \pm 0.148^{\mathrm{a}}$ & $4.027 \pm 0.279^{\mathrm{a}}$ \\
\hline Retroperitoneal fat mass (g) & $3.499 \pm 0.488^{\mathrm{a}}$ & $1.740 \pm 0.232^{\mathrm{b}}$ & $3.552 \pm 0.231^{\mathrm{a}}$ & $3.148 \pm 0.358^{a}$ \\
\hline Mesenteric fat mass (g) & $2.606 \pm 0.222^{\mathrm{a}}$ & $1.672 \pm 0.112^{\mathrm{b}}$ & $2.656 \pm 0.180^{\mathrm{a}}$ & $2.557 \pm 0.281^{\mathrm{a}}$ \\
\hline
\end{tabular}

C60 $(n=9)$, control group weaning at 21 days. EW, experimental groups early weaning at 14 days and treated with control (EWC60, n=10), flaxseed flour (EWFF60, $\mathrm{n}=11$ ) or flaxseed oil (EWFO60, $\mathrm{n}=10$ ) diet, respectively during period of 21 to 60 days. a,bValues displaying different superscripts are significantly different ( $<0.05$, one-way variance analysis, followed by Newman-Keuls post-test). C, control; EW, early weaning; FF, flaxseed flour; FO, flaxseed oil.

(protocol 597/2014). All procedures were in accordance with the Brazilian Science and Laboratory Animals Society provisions and the Guide for the Care and Use of Laboratory Animals published by the US National Institutes of Health (NIH Publication N 85-23, revised in 1996).

Wistar rats from the Laboratory Animals Center of the Fluminense Federal University were housed in a temperature-controlled room $\left(23 \pm 1{ }^{\circ} \mathrm{C}\right)$, humidity $(60$ $\pm 10 \%)$ with an artificial dark-light cycle (lights on from 7 am to $7 \mathrm{pm}$ ). Virgin female rats (3 months old) were caged with male rats, and, after mating, each female was placed in an individual cage with free access to water and standard laboratory food (Nuvilab®, Paraná, Brazil).

Within $24 \mathrm{~h}$ of birth, excess pups were removed, and only six male pups were kept per dam, a procedure maximizing lactation performance (16). During lactation period dams were fed a control diet containing 7 $\mathrm{g}$ soybean oil and $20 \mathrm{~g}$ casein $/ 100 \mathrm{~g}$, in agreement with American Institute of Nutrition (AIN-93G) recommendations (17). Control group pups $(C, n=9)$ were separated from their mothers on the 21st postnatal day. Pups in early weaning group $(\mathrm{EW}, \mathrm{n}=31)$ were separated from their mothers on the 14th postnatal day $(9,18)$. Due to procedure difficulties for checking the non-maternal separated pups, free access to drinking water and control diet was not evaluated for $C$ and EW pups until day 21. After separation from their mothers, rats from $C$ and $E W$ groups were held together in their original cage (up to six pups per cage).

At 21 days, body mass of six rats of control (C21, $n=6)$ and six rats of EW (EW21, n=6) group were evaluated. They were then anesthetized with Thiopentax ${ }^{\circledR}$ (Sodium thiopental, $0.1 \mathrm{mg} / 100 \mathrm{~g}$ ) and euthanized by exsanguination. Intra-abdominal fat mass were dissected and weighed. Masses were expressed as absolute $(\mathrm{g})$ and relative $(\mathrm{g} / 100 \mathrm{~g})$ mass (adjusted to body mass).

After 21 days, control animals (C60, n=9) were fed with control diet containing $20 \mathrm{~g}$ casein, $52.95 \mathrm{~g}$ cornstarch, $7 \mathrm{~g}$ soybean oil and $5 \mathrm{~g}$ fiber/ $100 \mathrm{~g}$. EW animals were divided into three groups: EW fed with control diet (EWC60, $\mathrm{n}=10$ ); EW fed with diet containing $25 \mathrm{~g}$ flaxseed flour, 45.84 of cornstarch and $15 \mathrm{~g}$ casein/ 100g (EWFF60, $\mathrm{n}=11$ ); and EW fed with a diet containing $7 \mathrm{~g}$ flaxseed oil, $52.95 \mathrm{~g}$ cornstarch, $5 \mathrm{~g}$ fiber and $20 \mathrm{~g}$ casein/ $100 \mathrm{~g}$ (EWFO60, n=10). Diets have same amounts of sucrose $(20 \mathrm{~g})$, mineral $(3.5 \mathrm{~g})$ and vitamin mix $(1 \mathrm{~g})$, L-cystine $(0.3 \mathrm{~g})$ and choline bitartrate $(0.25 \mathrm{~g})$, per $100 \mathrm{~g}$. Flaxseed flour contains $17 \%$ protein, $45 \%$ carbohydrate and $26 \%$ fat, while the flaxseed oil contain 3.66g $\alpha$-linolenic acid and $0.86 \mathrm{~g}$ linoleic acid for each $7 \mathrm{~g}$. The $25 \mathrm{~g} / 100 \mathrm{~g}$ flaxseed flour aimed to meet entire recommended fiber intake, and oil addition not being necessary to as this seed is a source of this component (18).

At 60 days, C60, EWC60, EWFF60 and EWFO60 groups were euthanized by exsanguination as described for C21 and EW21 animals. Intra-abdominal fat mass (Gonadal, retroperitoneal and mesenteric) were dissected and weighed. Retroperitoneal fat samples were collected and fixed in buffered formaldehyde, for morphological analyses. Tissue was embedded in paraffin, cut into 5-mm sections, and stained with hematoxylin-eosin (HE). Profiles with at least 100 adipocytes were randomly selected and captured for each animal, for morphometric analyses. Sectional area of adipocytes ( $\mathrm{mm} 2)$ was determined on digital images (TIFF format, 36 bit color, 1360 X 1024 pixels) acquired with an Optronics CCD video camera system and Olympus BX40 light microscope and analysed with the U.S. National Institutes of Health IMAGE-J software http: / / rsbweb.nih.gov/ij/(NIH, USA) $(13,14)$.

Statistical analyses were carried out using Graph Pad Prism statistical package version 5.0, 2007 (San Diego, CA, USA). The results at 21 days were analyzed by Student's t-test. The remaining results were analyzed using oneway variance analysis, followed by Newman-Keuls posttest and expressed as means \pm S.E.M. with significance level of 0.05 .

\section{Results}

At 21 days, experimental group shown lower absolute $(\mathrm{P}<0.05$, EW21: $0.199 \pm 0.038$ v. C21: $0.442 \pm 0.064 \mathrm{~g})$ and relative $(\mathrm{P}<0.05$, EW21: $0.544 \pm 0.081 \mathrm{v}$. $\mathrm{C} 21: 0.966 \pm 0.127$ $\mathrm{g} / 100 \mathrm{~g}$ ) intra-abdominal fat mass.

At 60 days, EWC60 group shown lower $(\mathrm{P}<0.05)$ 
intra-abdominal (absolute and relative), gonadal, retroperitoneal and mesenteric fat mass when compared to the other groups (Table 1 ).

Adipocytes area were lower $(\mathrm{P}<0.05)$ in experimental groups (EWC60: $1349 \pm$ 95.27; EWFF60: $1877 \pm 94.09$ and EWFO60: $1953 \pm 112.20 \mu \mathrm{m} 2)$ compared to control group $(2695 \pm 182.80 \mu \mathrm{m} 2)$. EWC60 shown lower $(\mathrm{P}<$ $0.05)$ adipocytes area compared to EWFF60 and EWFO60 groups (Figure 1).

\section{Figure 1}

Area of the adipocytes (a) and photomicrographs of the adipocytes, staining with $\mathrm{HE}$, original magnification (200X). C60 (n=9, b) and EWC60 (n=10, c) groups treated with control diet. EWFF60 (n=11, d) and EWFO60 ( $n=10$, e) treated with diet containing $25 / 100 \mathrm{~g}$ flaxseed flour or $7 \mathrm{~g} / 100 \mathrm{~g}$ flaxseed oil, respectively, and analyzed at 60 days. a,b,cValues displaying different superscripts are significantly different $(p<0.05$, one-way variance analysis, followed by Newman-Keuls post-test). C, control; EW, early weaning; FF, flaxseed flour; FO, flaxseed oil; HE, hematoxylin-eosin

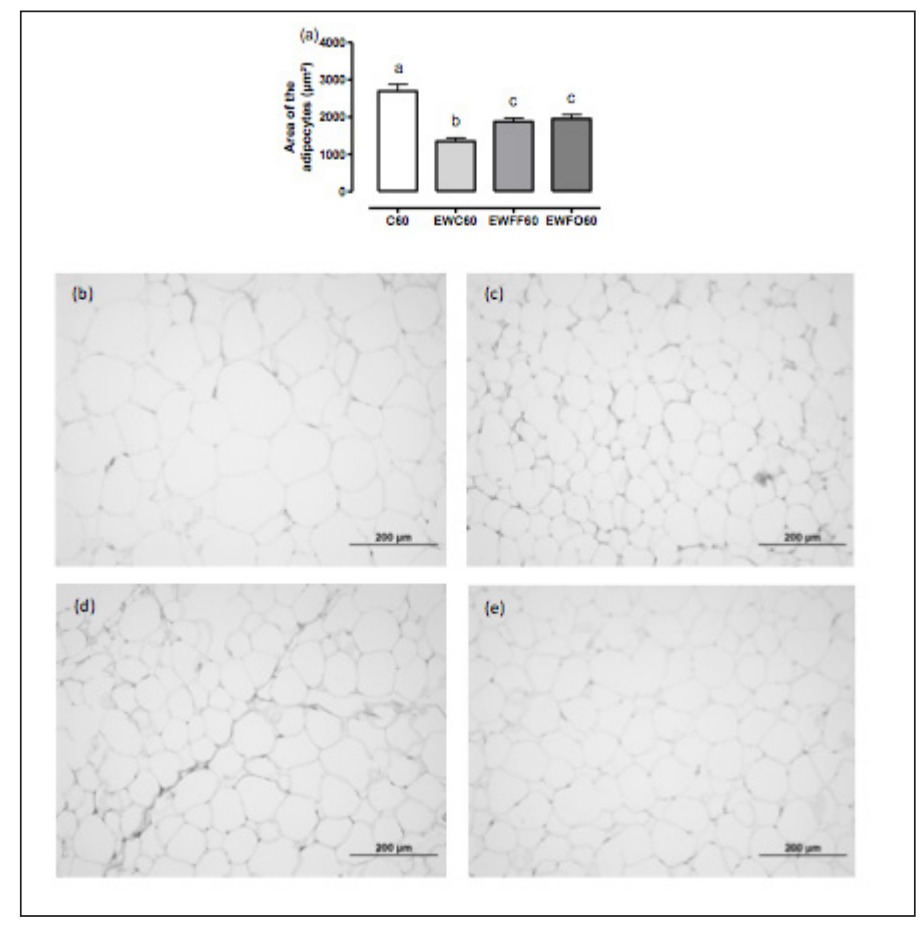

\section{Discussion}

Infancy is a critical period of growth and physiological development, in which breast milk plays important role for infant nutrition. Deviations in growth in early life are associated with increased risk of disease in the short and long term $(4,19)$. We have considered period of 14-21 days corresponds to second 6 months of life in humans because at 14 days of life, rats begin consumption of solid food, at this age, pups still breastfeed $(18,20)$. At birth, body fat accounts for $\sim 15 \%$ of weight, and this increases to $\sim 25 \%$ at six months, peaking at $\sim 30 \%$ at 12 months. 4
However, precocious interruption of lactation was associated with lower body mass and intra-abdominal fat mass development at 21 days.

Babies in lower socioeconomic groups have sustained degrees of nutritional deprivation, usually followed by continuous malnutrition until early adolescence (21). In the present study, food intake was similar between groups (18), even so EWC60 group showed lower body mass and intra-abdominal fat development, corroborating with Costa et al. (22) that observed, after maternal malnutrition during lactation, lower body development and permanent changes in Wistar male rat metabolism and structure at 60 days.

One of the strategies for the treatment of malnutrition is to increase energy density of foods by increasing the lipid content. However, high fat diet did not contribute to recovery from maternal malnutrition during lactation (20). Contrary, EWFF60 and EWFO60 groups, treated with normo -caloric and -fat diets containing flour or flaxseed oil, respectively, showed recovery of intraabdominal fat mass. The composition may be more relevant than high energy density in the dietary treatment of malnutrition.

Flaxseed (Linum usitatissimum) has been described as an excellent alpha- linolenic acid (ALA, 18: 3n-3) source, presenting an average of $30 \%$ lipids in its composition, with $51 \%$ to $55 \%$ corresponding to $\operatorname{ALA}(23,24)$. Regarding adiposity depots, Costa et al. (13) and Ribeiro et al. (14) reported lower intra-abdominal adipocyte area in rats fed flaxseed diet, in early and adult life, respectively. ALA induces the fatty acid oxidation genes through peroxisome proliferator-actived receptor alpha $(P P A R \alpha)$ and the suppression of lipogenic genes through sterol regulatory element-binding protein (SREBP-1C), decreasing the size of adipocytes $(25,26)$. Although the present study did not displayed blood parameters regarding to obesity and or metabolism, these pathways help to explain the decrease in adipocyte area in EWFF60 and EWFO60 groups.

However, Boueri et al.9 after evaluation of body composition by dual-energy X-ray absorptiometry, observed a phenomenon of "catch-up fat" in EWFO60 group, because rats showed lower lean and bone mass, and fat mass similar to control group. Findings support an adverse effect of flaxseed oil on adiposity, with likely implications for obesity in adult life. Contrary, flaxseed flour was associated with adequate adiposity recovery regardless of body mass. Probably the composition of flour contributed to the outcomes, because in addition to ALA, flaxseed flour contains high-quality protein, carbohydrates and minerals distributed among phenolic acids, lignin and hemicelluloses $(13,14,18)$.

The potential implications of the present findings for the treatment of malnutrition in early period of life are of great interest and importance. Flour and flaxseed oil diets contributes to recovery of intra-abdominal adiposity in young life. Nevertheless, further studies are necessary to clarify if flour and flaxseed oil treatment, after precocious 
interruption of lactation, contributes to obesity prevention in adult life.

Acknowledgments: The authors are thankful to the Laboratory of Nutrition and Functional Assessment (LANUF), College of Nutrition, Federal Fluminense University for technical assistance and use of DXA equipment. Also thank Coordination for the Enhancement of Higher Education Personnel (CAPES) and National Counsel of Technological and Scientific Development (CNPq).

Compliance with Ethical Standards: This work was funded by The State of Rio de Janeiro Carlos Chagas Filho Research Foundation (grant number 103373/2012).

Ethical approval: The protocol used to deal with experimental animals was approved by Ethics Committee on Animal Research of Fluminense Federal University, Niterói-RJ, Brazil (protocol 597/2014). All procedures are in accordance with the provisions of Brazilian Society of Science and Laboratory's Animals and the Guide for the Care and Use of Laboratory Animals.

Conflict of interest: The authors declare that there no conflict of interest.

\section{References}

1. Portela DS, Vieira TO, Matos SMA, de Oliveira NF, Vieira GO. Maternal obesity, environmental factors, cesarean delivery and breastfeeding as determinants of overweight and obesity in children: results from a cohort. BMC Pregnancy Childbirth 2015;15: 94

2. Assunção ML, Ferreira HS, Coutinho SB, Santos LMP, Horta BL. Protective effect of breastfeeding against overweight can be detected as early as the second year of life: a study of children from one of the most socially-deprived areas of brazil. J Health Popul Nutr 2015;33: 85-91

3. Denney-Wilson E, Laws R, Russell CG, Ong K, Taki S, Elliot R, Azadi L, Lymer S, Taylor R, Lynch J, Crawford D, Ball K, Askew D, Litterbach EK, Campbell KJ. Preventing obesity in infants: the growing healthy feasibility trial protocol. BMJ Open 2015;5 (11): e009258

4. O'Sullivan A, Farver M, Smilowitz JT. The influence of early infant-feeding practices on the intestinal microbiome and body composition in infants. Nutr Metab Insights 2015;8: 1-9

5. World Health Organization. Global strategy for infant and young child feeding. WHO: Geneva, Switzerland

6. Parsons TJ, Power C, Manor O. Fetal and early life growth and body mass index from birth to early adulthood in 1958 British cohort: longitudinal study. BMJ 2001;323: 1331-1335

7. Younes-Rapozo V, de Moura EG, Lima NS, Barradas PC, Manhães AC, de Oliveira E, Lisboa PC. Early weaning is associated with higher neuropeptide Y (NPY) and lower cocaine- and amphetamine-regulated transcript (CART) expressions in the paraventricular nucleus (PVN) in adulthood. Br J Nutr 2012;108: 2286-2295

8. Albuquerque Maia L, Lisboa PC, de Oliveira E, Lima NS, da Costa CAS, de Moura EG. Two models of early weaning decreases bone structure by different changes in hormonal regulation of bone metabolism in neonate rat. Horm Metab Res 2012;44: 1-6

9. Boueri BFC, Pessanha CR, da Costa LR, Ferreira MR, Melo HS, de Abreu MDC, Pessoa LR, da Silva PCA, Pereira AD, Ribeiro DC, de Meneses JA, da Costa CAS, Boaventura GT. Body composition in male rats subjected to early weaning and treated with diet containing flour or flaxseed oil after 21 days until 60 days. J Dev Orig Health Dis 2015;6: 553-557
10. Rat behavior and biology. How old is a rat in human years? Available at: http: / / www.ratbehavior.org/ ratyears. Accessed December, 2015

11. Nobre JL, Lisboa PC, Lima NS, Franco JG, Neto JFN, de Moura EG, de Oliveira E. Calcium supplementation prevents obesity, hyperleptinaemia and hyperglycaemia in adult rats programmed by early weaning. Br J Nutr 2012;107: 979-988

12. Bieswal F, Ahn M, Reusens B, Holvoet P, Raes M, Rees WD, Remacle C. The importance of catch-up growth after early malnutrition for the programming of obesity in male rat. Obesity 2006;14: 1330-1343

13. Costa CAS, da Silva PCA, Ribeiro DC, Pereira ADD, Santos AS, Maia LA, Ruffoni LDG, de Santana FC, de Abreu MDC, Boueri BFC, Pessanha CR, Nonaka KO, Mancini-Filho J, Nascimento-Saba CCA, Boaventura GT. Body adiposity and bone parameters of male rats from mothers fed diet containing flaxseed flour during lactation. J Dev Orig Health Dis 2015;7: 1-6

14. Ribeiro DC, Pereira AD, Silva PCA, Santos AS, Santana FC, Boueri BFC, Pessanha CR, Abreu MDC, Mancini-Filho J, Silva EM, Nascimento-Saba CCA, Costa CAS, Boaventura GT. Flaxseed flour (Linum usitatissinum) consumption improves bone quality and decreases the adipocyte area of lactating rats in the post-weaning period. Int J Food Sci Nutr 2015;13: 1-6

15. Schroeder N, Rushovich B, Bartlett E, Sharma S, Gittelsohn J, Caballero B. Early obesity prevention: a randomized trial of a practice-based intervention in 0-24-month infants. J Obes 2015;795859

16. Fishbeck KL, Rasmussen KM. Effect of repeated cycles on maternal nutritional status, lactational performance and litter growth in ad libitum-fed and chronically food-restricted rat. J Nutr 1987;117: 1967-1975

17. Reeves PG. Components of the AIN-93 diets as improvements in the AIN76A diet. J Nutr 1997;127: 838-841

18. Pessanha CR, Boueri BFC, da Costa LR, Ferreira MR, Melo HS, de Abreu MD, Pessoa LR, da Silva PC, Pereira AD, Ribeiro DC, de Meneses JA, da Costa CAS, Boaventura GT. Brain development in male rats subjected to early weaning and treated with diet containing flour or flaxseed oil after 21 days until 60 days. J Dev Orig Health Dis 2015;6: 268-271

19. Titi Y, Yumei Z, Yibing N, Lili Y, Defu M, Yingdong Z, Xiaoguang Y, Wenjun LI, Junkuan W, Peiyu W. Breast milk macronutrient composition and the associated factors in urban Chinese mothers. Chin Med J 2014;127: 1721-1725

20. Oliveira LS, Silva LP, Silva AI, Magalhães CP, Souza SL, Castro RM. Effects of early weaning on the circadian rhythm and behavioral satiety sequence in rats. Behav Process 2011;86: 119-124

21. Morgane PJ, Austin-Lafrance R, Bronzino J, Tonkiss J, Díaz-Cintra L, Kemper T, Galler JR. Prenatal malnutrition and development of the brain. Neurosci Biobehav Rev 1993;17: 91-128

22. Costa CAS, Alves EG, Gonzalez GPL, Barbosa TBC, Carlos AS, Lima VD, Nascimento R, Moura EG, Nascimento-Saba CCA. Evaluation of body development, fat mass and lipid profile in rats fed with high-PUFA and -MUFA diets, after neonatal malnutrition. Br J Nutr 2009;101: 1639-1644

23. Leite CDFC, Vicente GC, Suzuki A, Pereira AD, Boaventura GT, Santos RM, Velarde LGC. Effects of flaxseed on rat milk creamatocrit and its contribution to offspring body growth. J Ped (Rio J) 2012;88: 74-78

24. Pacheco JT, Delaprame JB, Boaventura GT. Impact of dietary flaxseed (linum usitatissimum) supplementation on biochemical profile in healthy rats. Nutr Hosp 2011;26: 798-802

25. Hsu SC, Huang CJ. Reduced fat mass in rats fed a high oleic acid-rich safflower oil diet is associated with changes in expression of hepatic PPAR $\alpha$ and adipose SREBP-1c-regulated genes. J Nutr 2006;136: 1779-1785

26. Massiera F, Saint-Marc P, Seydoux J, Murata T, Kobayashi T, Narumiya S, Guesnet P, Amri EZ, Negrel R, Ailhaud G. Arachidonic acid and prostacyclin signaling promote adipose tissue development: a human health concern? J Lipid Res 2003;44: 271-279 